\title{
Optimal Inventory Policy in a Closed Loop Supply Chain System with Multiple Periods
}

\author{
A. Sasikumar ${ }^{1}$ (D), K. Natarajan ${ }^{1}$ (D), MuthuRathna Sapabathy Ramasubramaniam² (D), \\ K.K. Deepaknallasamy ${ }^{1}$ (D) \\ 'Anna university (India) \\ ${ }^{2}$ Loyola Institute of Business Administration (India) \\ kumarsasi795@gmail.com, knatarajan27@gmail.com, rams.m@,liba.edu, deepaknallasamy@.gmail.com
}

Received: December 2016

Accepted: February 2017

\section{Abstract:}

Purpose: This paper aims to model and optimize the closed loop supply chain for maximizing the profit by considering the fixed order quantity inventory policy in various sites at multiple periods.

Design/methodology/approach: In forward supply chain, a standard inventory policy can be followed when the product moves from manufacturer, distributer, retailer and customer but the inventory in the reverse supply chain of the product with the similar standard policy is very difficult to manage. This model investigates the standard policy of fixed order quantity by considering the three major types of return-recovery pair such as commercial returns, end- ofuse returns, end -of- life returns and their inventory positioning at multiple periods. The model is configured as mixed integer linear programming and solved by IBM ILOG CPLEX OPL studio.

Findings: To find the performance of the model a numerical example is considered for a product with three Parts (A which of 2nos, B and C) for 12 multiple periods. The results of the analysis show that the manufacturer can know how much should to be manufacture in multiple periods based on Variations of the demand by adopting the FOQ inventory policy at different sites considering its capacity constraints. In addition, it is important how much of parts should be purchased from the supplier at the given 12 periods. 
Originality/value: A sensitivity analysis is performed to validate the proposed model two parts. First part of the analysis will focus on the inventory of product and parts and second part of analysis focus on profit of the company. The analysis which provides some insights in to the structure of the model.

Keywords: closed loop supply chain (CLSC), fixed order quantity (FOQ), mixed- integer linear programming (MILP), inventory

\section{Introduction}

Reverse logistics is a very vast field of study with various issues being addressed such as remanufacturing, commercial returns, end-of-life returns and so on. Designing a model in closed loop supply chain would be an arduous task and may result in inefficient network Rogers and Tibben-Lembke (2001). Due to environmental impact and economic performance, there should be proper management to maintain the flows of products and parts to reduce the negative impact on the environment. This necessitates a proper mix of recovery options which is great a challenge in reverse supply chain. The Options for the recovery of returned products consists of reuse, resale, repair, and refurbishing, remanufacturing, cannibalization and recycling (Thierry, Salomon, Van Nunen \& Van Wassenhove, 1995). A portion of the returned products are sent to the collecting site from where repairable products are sent to the repair site. In remanufacturing and recycling process, used products are disassembled into parts in the disassembled site and transported back to the manufacturing site. In this paper, we propose a CLSC network with the objective of maximizing the profit by maintain the fixed order inventory policy.

\section{Literature Review}

There is a considerable body of research available in Reverse logistics (RL) network, for instance (Fleischmann, Bloemhof-Ruwaard, Dekker, Van der Laan, Van Nunen \& Van Wassenhove, 1997; Sasikumar \& Kannan, 2008a, 2008b, 2009). The RL could be categorized broadly in to 3 major areas, namely distribution planning, inventory control and production planning as reviewed by (Fleischmann et al., 1997). While CLSC have been an area of active research in the past decade, little contribution had been made in integration of forward and reverse flow of inventory positioning with the influence of multiple products, uncertainty, and product life cycle. It was (Srivastava \& Srivastava, 2006) who proposed a framework to manage the product returns by estimating selected categories of products. They have shown the impact of 
quality and timing of returns on the overall RL network design. Recently Amin and Zhang (2014) proposed a model to configure a CLSC network including multiple plants, products, technologies, demand markets and collection sites for minimizing the total cos. The results are analyzed and different efficient solutions are calculated by means of multi-objective methods. A heuristic approach was proposed by Lee, Gen and Rhee (2008) for minimization of total shipping cost of RL in a multi stage network.

Product recovery options in RL were not explored before Sasikumar, Kannan and Haq (2010) developed a mixed integer linear programming model for truck tyre re-manufacturing company to maximize the profit of multi echelon reverse logistic network. They concluded value creation is possible by means of successful product recovery process in the case of used tyre segments. Their sensitivity analysis has been done to find the maximum allowable distance between initial collection point and the customers. An important question of RL namely remanufacturing in which a model that jointly determines the quantities of re-manufactured product, the production quantities of new branded product and the acquisition prices of used product was addressed in Shi, Zhang and Sha (2011).

Apart from the context of product recovery options, the RL integration with forward chain was addressed by Kannan, Noorul-Haq and Devika (2009) who integrated the forward logistics multi-echelon distribution inventory supply chain model and closed loop multi-echelon distribution inventory supply chain. They formulated the model using genetic algorithm and particle swarm optimization techniques for built -to-order environment. The model is validated with two case studies one in a tyre manufacture and other from plastic goods manufacturer.

For proper inventory management of single period in CLSC flow, (Mitra, 2012) developed deterministic and stochastic model for a two echelon system. The developed model justify with numerical examples that a higher rate of return and a higher correlation between demand and return reduce the variability of net demand. Although several models are available for the integration of forward and reverse logistics network, (Amin \& Zhang, 2012a) proposed an integrated model with two phases. In the first phase, a supplier selection with evaluation of quality criteria was framed by fuzzy method. In the second phase they identified which supplier and refurbishing site should be selected and find out the optimal number of parts and products in the CLSC network. Due to increasing adoption of RL processes, integration of distribution channel in the supply chain network becomes important.

Subramanian, Ramkumar, Narendran and Ganesh (2013) focused on integration with four variants of RL network with dedicated warehouse delivery locations. They found that for different scenarios, a single product, single period will perform well with constant demand and uncertain returns. In another study Saeedi, Mohammadi and Torabi (2015) has studied the capacity determination in CLSC by establishing the queue system. Here the queue cost and fixed opening cost are obtained by modeling a mixed integer nonlinear programming. Another author Benedito and Corominas (2010) has studied by calculating the 
optimal manufacturing and remanufacturing capacity of the reverse system by random behavior of the quantity, quality and timing of units collected in through the system. The results show that product mix is influenced by the probability of end of usage product collected and returns.

Most of the integrated models found in CLSC devise optimal inventory, policies, location of various sites and selection of suppliers, all for a single period. The impact of product life cycle and the corresponding variation in demand on the total supply chain were not focused in CLSC network. This gap was first identified by Georgiadis, Vlachos and Tagaras (2006) with the implications of capacity planning issues in the process of PLC. Their result shows that collection and remanufacturing capacity policies are insensitive to the total product demand. Later (Ahiska \& King, 2010) developed optimal inventory policies for CLSC during various stages of product lifecycle. The results of their analysis show that frequent revision of the inventory policy is important over the entire life cycle of the product. Later Mishra (2013) developed a model for optimizing the total inventory cost of deteriorating items by taking demand rate and holding cost as linear function of time. His findings show that there are efficient ways to reduce deteriorating inventory by adopting preservation technology.

Amin and Zhang (2012b) proposed a model to determine the quantity of new products and parts to be produced in a single period. Their study indicates that the manufacturer should take in to account key factors such as production capacity, demand, supplier capacity, end-of-life and commercial returns.

In reality, remanufacturing industry deals with multiple products, multiple parts in a multiple periods. This issue was addressed by El-Sayed, Afia and El-Kharbotly (2010) to maximize the profit a CLSC network structure consisting of three echelons in the forward direction (suppliers, facilities and distribution centers) and two echelons, in the reverse direction (disassembly, and redistribution centers) with demand as uncertain was developed. In real life situation for recovery options, parts of a product will play a vital role at the various sites. By considering the parts in multi product, multi period a model (Özceylan \& Paksoy, 2013) proposed a model for determining the location of plants and retailers with optimal amount of products to be transportation and parts to be disassembled. Roghanian and Pazhoheshfar (2014) developed a model for multi-product, multi-stage reverse logistics network problem for the return products. It determines not only the subsets of disassembly centers and processing centers to be opened but also the transportation strategy that will satisfy demand imposed by manufacturing centers and recycling centers with minimum fixed opening cost and total shipping cost.

When designing a reverse supply chain under demand uncertainly Cardoso, Barbosa-Póvoa and Relvas (2013) formulated a mathematical model by considering simultaneously production, distribution and reverse logistics activities. The model defined for maximization of the expected net present value and the results provide details on sizing and location of plants, warehouses and retailers, definition of processes to install, establishment of forward and reverse flows and inventory levels to maintain. Recently author 
Jindal, Sangwan and Saxena (2015) presented a model for optimization of uncertainty parameters in a multi product, multi echelon CLSC with multi time. This model illustrate the optimal location and allocation of products/parts at each facility, number of products to be remanufactured, number of parts to be purchased from external suppliers and inventory level of products/parts in order to maximize the profit to the organization.

In summary, there have been a lot of related contributions that are worth noting in managing a CLSC. However, the review brings forth that though the problems of PLC in CLSC has been researched, there is a requirement for a more comprehensive treatment of PLC and study its impact during the CLSC design stage. Hence an attempt was made by us Sasikumar, Natarajan and Ramasubramaniam (2016) to interlink the PLC with CLSC network for single product, single part and for time period of 16 . With an example illustrated in the model show that the decision variable involved in inventory positioning at various sites depend on the stage of PLC. The net result of the study shows that the standard inventory policy FOQ is not used in the CLSC system, when there is product and part mix. In this paper we propose to develop to model to determine the inventory of product and parts at various site in a CLSC by considering the FOQ policy.

\section{Problem Definition}

There are various types of CLSC frame work are available. Among all these type of the frame work, we propose a generalized form of CLSC framework with the initial inventory at various sites and optimized end period inventory at various site with demands at multiple period. To maintain model parsimony, the framework of Amin and Zhang (2012b) of reverse logistics consist of a manufacturer, collection site, repair site, disassembly site, disposal site and recycling sites as shown in the Figure 1. After using the products, some of the customers return the used products. The returned products are then collected during different periods at collection site and are segregated in to two types of returns. One, commercial returns of the returns products which are sent to the repair site for refurbishing and small repair. Second, the products are taken to the disassembly sites for disassembled into parts. The unused parts can be disposed to the disposed site and the usable parts in the form of end -of- life can be sent to recycling site for processing and the good parts in the form of end- of- use taken to part inventory during multiple periods.

The purpose of this research work is to develop a model to determine the quantity of products and parts at various sites for multiple periods by using fixed order inventory policy to maximize the profit of the CLSC. In this model three types product recovery are considered (i) commercial returns of the product, (ii) end of life returns and (iii) end of use returns along with important aspect of inventory positioning. 
Further, if the demands of the product during multi period are more than the returned products then manufacturer has to produce new products. For purpose of calculating cost, the setup cost, inventory cost, shipping cost and maximum capacity of repair site, disassembly site, recycling site, and manufacturing site are considered. The objective function is to maximize the profit of manufacturer with the various costs associated with it.

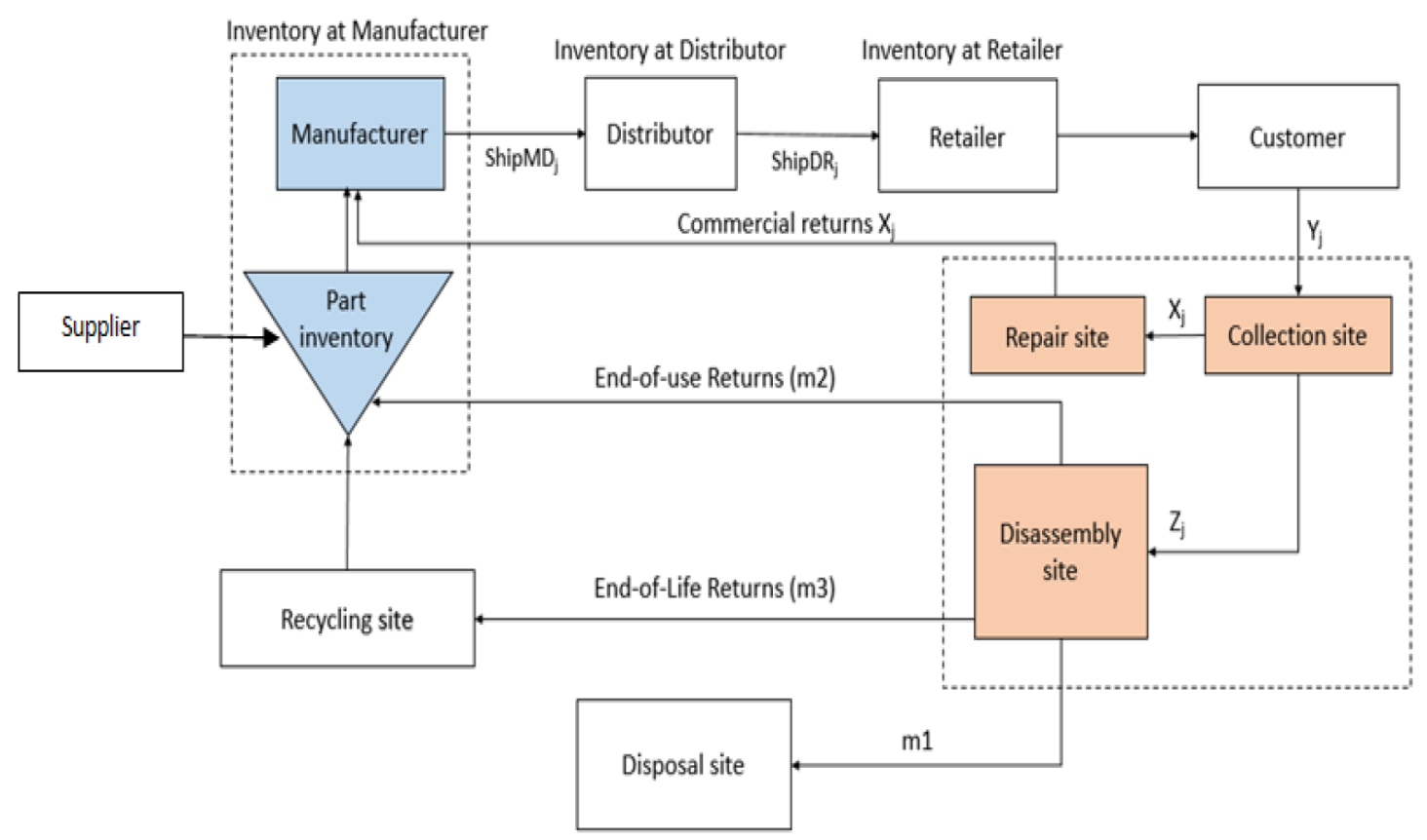

Figure 1. Proposed framework of CLSC

In addition to the above cost unit inventory holding cost, ordering cost, back order cost, shipment cost, set up cost and capacity constraints of repair site, disassembly site and recycling site are also taken in to account. Most of the recycling industries like battery, printer and electronic components etc are found to adopt this kind of CLSC framework of Amin and Zhang (2012b). 


\section{Model Formulations and Assumptions}

The Indices, Parameters and its associated decision variables and the mathematical model formation of the proposed closed loop supply chain are shown in the table. For computation purpose, the various input data are taken from the literature Amin and Zhang (2012b). The assumptions involved in this model are as follows:

- The CLSC is assumed to be centralized at manufacturer. Hence the manufacturer is responsible for the entire cost of the supply chain network.

- The Proposed model is a multi- period model.

- The demands of product is known for all the periods

- The models consist of one product and three major parts of $\mathrm{A}, \mathrm{B}$ and $\mathrm{C}$ in which part $\mathrm{A}$ is of two quantities.

- The capacity of the collection site is unlimited.

- The initial inventory of the manufacturer, Distributor and retailer is known.

- Lead time for each site is taken as one.

- Collecting site, Disassembly site and Repair site are located under one roof and their shipment lead time is considered as zero.

- Reorder level and ordering quantity are known at Retailer, Distributor and Manufacturing site.

- Part Inventory is located inside manufacturing site.

- If the quantity of parts from Recycling site is not enough to meet the requirement of the manufacturer then manufacturer should procure from external supplier.

- Shipment cost for product and part at each site is known.

- After Disposal of parts an equal percentage of parts will be sent to Part inventory and recycling site from Disassembly site 


\section{Indices}

\begin{tabular}{|l|l}
\hline$t$ & Set of period $\mathrm{t}=1,2, . . \mathrm{T}$
\end{tabular}

Decision Variables

\begin{tabular}{|c|c|}
\hline$I n v \_M A_{i t}$ & Inventory of Part $\mathrm{A}$ in manufacturing site at period $t$ \\
\hline$I n v_{-} M B_{i t}$ & Inventory of Part B in manufacturing site at period $t$ \\
\hline$I n v_{-} M C_{i t}$ & Inventory of Part $\mathrm{C}$ in manufacturing site at period $t$ \\
\hline Start_Inv_M $M_{j t}$ & Inventory of Product in manufacturing site at period $t$ \\
\hline End_Inv_M $M_{j t}$ & End period Inventory of product at manufacturer at period $t$ (After shipment to distributor) \\
\hline Start_Inv_D $D_{i t}$ & Inventory of Product in Distributor site at period $t$ \\
\hline End_Inv_D $D_{j t}$ & End period Inventory of product at Distributor at period $t$ (After shipment to retailer) \\
\hline Start_Inv_R $\mathrm{R}_{\text {it }}$ & Inventory of Product in Retailer site at period $t$ \\
\hline End_Inv_R $\mathrm{R}_{j t}$ & End period Inventory of product at Retailer at period $t$ (After customer received from the retailer) \\
\hline Inv_Dis $s_{j t}$ & Inventory of product at disassembly site at period $t$ \\
\hline Inv_Dis $s_{i t}$ & Inventory of Part at disassembly site at period $t$ \\
\hline Inv_Dis_Ait & Inventory of Part A at disassembly after disassembly at period $t$ \\
\hline Inv_DisBit & Inventory of Part B at disassembly after disassembly at period $t$ \\
\hline Inv_DisCit & Inventory of Part $\mathrm{C}$ at disassembly after disassembly at period $t$ \\
\hline Inv_DisDS & Inventory of parts waiting at disassembly for shipment to disposal site at period $t$ \\
\hline$I n v \_R e p_{j t}$ & Inventory of Products at repair site at period $t$ \\
\hline$I n v_{-} R e c_{i t}$ & Inventory of parts at recycling site at period $t$ \\
\hline Inv_Dis $A B C_{i t}$ & Inventory of parts at disassembly site waiting to send to recycling site and part inventory \\
\hline$A_{j t}$ & Binary variable for reorder point at retailer at period $t$ \\
\hline$B_{j t}$ & Binary variable for reorder point at distributor at period $t$ \\
\hline$C_{j t}$ & Binary variable for reorder point at Manufacturer at period $t$ \\
\hline$D_{j t}$ & Binary variable for shipment of products at repair site at period $t$ \\
\hline$E_{i t}$ & Binary variable for shipment of Parts from disassembly site to recycle site and part inventory at period $t$ \\
\hline$G_{i t}$ & Binary variable for shipment of Parts from recycle site to part inventory at period $t$ \\
\hline$I_{\text {it }}$ & Binary variable for shipment of Parts from disassembly site to disposal site at period $t$ \\
\hline$K_{i t}$ & Binary variable for trigger point for product exceeds the disassembly site capacity \\
\hline$B L \_R_{j t}$ & Back order of product at retailer at period $t$ \\
\hline$B L \_D_{j t}$ & Back order of product at distributor at period $t$ \\
\hline$B L \_M_{j t}$ & Back order of product at manufacturer at period $t$ \\
\hline ShipDR $_{j t}$ & Shipment of products from the distributor to retailer \\
\hline $\operatorname{ship} M D_{j t}$ & Shipment of products from the Manufacturer to retailer \\
\hline ShipRepM $M_{j t}$ & Shipment of products from the repair site to manufacturer \\
\hline $\operatorname{ShipSP} A_{i t}$ & Shipment of Part A from supplier to part inventory at period $t$ \\
\hline ShipSPB ${ }_{i t}$ & Shipment of Part B from supplier to part inventory at period $t$ \\
\hline ShipSPC & Shipment of Part C from supplier to part inventory at period $t$ \\
\hline $\operatorname{ShipRCP} A_{i t}$ & Shipment of Part A from recycling site to part inventory at period $t$ \\
\hline$S h i p R C P B_{i t}$ & Shipment of Part B from recycling site to part inventory at period $t$ \\
\hline ShipRCPC $C_{i t}$ & Shipment of Part $\mathrm{C}$ from recycling site to part inventory at period $t$ \\
\hline ShipDSPA $A_{i t}$ & Shipment of Part A from disassembly site to part inventory at period $t$ \\
\hline ShipDSPB ${ }_{i t}$ & Shipment of Part B from disassembly site to part inventory at period $t$ \\
\hline
\end{tabular}




\begin{tabular}{|c|c|}
\hline ShipDSPC it & Shipment of Part $\mathrm{C}$ from disassembly site to part inventory at period $t$ \\
\hline ShipDSRCA $A_{i t}$ & Shipment of Part A from disassembly site to recycle site at period $t$ \\
\hline ShipDSRCB ${ }_{i t}$ & Shipment of Part B from disassembly site to recycle site at period $t$ \\
\hline ShipDSRCC $C_{i t}$ & Shipment of Part $\mathrm{C}$ from disassembly site to recycle site at period $t$ \\
\hline ShipDSDP $P_{i t}$ & Shipment of parts from disassembly site to disposal site at period $t$ \\
\hline$X_{j t}$ & Units of product to be repaired in repair site at period $t$ \\
\hline$Y_{j t}$ & Units of product collected in collecting site at period $t$ \\
\hline$Z_{j t}$ & Units of return product to be disassembled at period $t$ \\
\hline$S 1_{i t}$ & Units of part A to be purchased from supplier at period $t$ \\
\hline$S 2_{i t}$ & Units of part B to be purchased from supplier at period $t$ \\
\hline$S 3_{i t}$ & Units of part $C$ to be purchased from supplier at period $t$ \\
\hline$E 1_{i t}$ & Units of part A that are obtained in recycling site at period $t$ \\
\hline$E 2_{i t}$ & Units of part B that are obtained in recycling site at period $t$ \\
\hline$E 3_{i t}$ & Units of part $\mathrm{C}$ that are obtained in recycling site at period $t$ \\
\hline$R 1_{i t}$ & Units of part A considered as end of use returns at period $t$ \\
\hline$R 2_{i t}$ & Units of part B considered as end of use returns at period $t$ \\
\hline $\mathrm{R} 3_{i t}$ & Units of part $\mathrm{C}$ considered as end of use returns at period $t$ \\
\hline$M F_{j t}$ & Units of product to be produced in manufacturer site at period $t$ \\
\hline$M F A_{i t}$ & Units of part A needed for manufacturer to produce a product $j$ at period $t$ \\
\hline$M F B_{i t}$ & Units of part B needed for manufacturer to produce a product $j$ at period $t$ \\
\hline$M F C_{i t}$ & Units of part $C$ needed for manufacturer to produce a product $j$ at period $t$ \\
\hline \multicolumn{2}{|r|}{ Parameters } \\
\hline$D \_R_{j t}$ & Demand at retailer \\
\hline$I_{r}$ & Initial inventory at retailer \\
\hline$I_{d}$ & Initial inventory at distributor \\
\hline$I_{m}$ & Initial inventory at manufacturer \\
\hline$s j$ & Unit selling price of the product \\
\hline ij & Unit direct manufacturing cost of a product \\
\hline$d j$ & Unit repair cost of a product \\
\hline Or & Ordering cost for retailer \\
\hline Od & Ordering cost for distributor \\
\hline Om & Ordering cost for manufacturer \\
\hline Cship_DR & Total shipment cost for products from distributor to retailer \\
\hline Cship_MD & Total shipment cost for products from manufacturer to distributor \\
\hline Cship_SM & Total shipment cost for parts from supplier to manufacturer \\
\hline Cship_DisREC & Total shipment cost for parts from disassembly to recycle site \\
\hline Cship_DisPI & Total shipment cost for parts from disassembly to Part inventory \\
\hline Cship_RecPI & Total shipment cost for parts from recycle to Part inventory \\
\hline Cship_DisDP & Total shipment cost for parts from disassembly to Disposal site \\
\hline Cship_REP & Total shipment cost for product from repair site to manufacturer \\
\hline DIS & Maximum capacity of the disassembly site \\
\hline CsColl & Unit collecting cost \\
\hline CsDis & Unit disassembly cost \\
\hline
\end{tabular}




\begin{tabular}{|c|c|}
\hline CsDSP & Unit disposal cost \\
\hline CsRcl & Unit recycle cost \\
\hline$a 1$ & Unit requirements of Part A to produce one unit of product $j$ \\
\hline$a 2$ & Unit requirements of Part B to produce one unit of product $j$ \\
\hline a3 & Unit requirements of Part $C$ to produce one unit of product $j$ \\
\hline $\operatorname{Pur} A$ & Unit purchase cost of part A from supplier \\
\hline Pur B & Unit purchase cost of part B from supplier \\
\hline Pur $C$ & Unit purchase cost of part $C$ from supplier \\
\hline$m 1$ & Maximum percentage of parts sent to disposal site \\
\hline$m 2$ & Maximum percentage of end of use returns \\
\hline$m 3$ & Maximum percentage of end of life returns \\
\hline$m 4$ & Maximum percentage of returns \\
\hline$m 5$ & Maximum percentage of product sent to repair site \\
\hline$m 6$ & Maximum percentage of product sent to disassembly site \\
\hline CR & Unit inventory cost at retailer \\
\hline$C D$ & Unit inventory cost at distributor \\
\hline$C M P$ & Unit inventory cost for product at manufacturer \\
\hline$C M P r$ & Unit inventory cost for part at manufacturer \\
\hline CDisP & Unit inventory cost at disassembly site for product \\
\hline CDisPr & Unit inventory cost at disassembly site for part \\
\hline Crep & Unit inventory cost at repair site \\
\hline Crec & Unit inventory cost at recycling site \\
\hline$B C r$ & Back order cost at retailer \\
\hline$B C d$ & Back order cost at distributor \\
\hline$B C m$ & Back order cost at manufacturer \\
\hline FOQR & Fixed order quantity for retailer \\
\hline FOQD & Fixed order quantity for distributor \\
\hline FOQm & Fixed order quantity for manufacturer \\
\hline$S$ & Maximum capacity of repair site \\
\hline MaxDis & Shipment capacity of truck disassembly to disposal site \\
\hline ShipDIS_RC_PI & Shipment trigger point for parts from disassembly site to recycle and part inventory \\
\hline $\mathrm{R}$ & Shipment trigger point for parts from Recycling site to part inventory \\
\hline$D S P A$ & Truck capacity of part A from disassembly to disposal site \\
\hline$D S P B$ & Truck capacity of part B from disassembly to disposal site \\
\hline$D S P C$ & Truck capacity of part $\mathrm{C}$ from disassembly to disposal site \\
\hline DSRCA & Truck capacity of Part A from disassembly to recycling site \\
\hline$D S R C B$ & Truck capacity of Part B from disassembly to recycling site \\
\hline DSRCC & Truck capacity of Part $C$ from disassembly to recycling site \\
\hline $\mathrm{RCPA}$ & Truck capacity of Part A from recycling to part inventory \\
\hline $\mathrm{RCPB}$ & Truck capacity of Part B from recycling to part inventory \\
\hline $\mathrm{RCPC}$ & Truck capacity of Part C from recycling to part inventory \\
\hline
\end{tabular}

Table 1. Shows the Indices, Decision Variables, and Parameters of the mathematical model 
Max Z [Revenue - Cost incurred at various sites (Retailer + Distributor + Manufacturer + collecting + Disassembly + Repair + Disposal + Recycling)]

The objective function is to maximize the total profit.

Revenue:

$$
\sum_{i=1}^{T} s_{j}\left(D_{-} R_{j t}\right)
$$

The Function (1) denotes the total revenue earned by selling the products.

Retailer cost:

$$
\operatorname{Ir}(C R)+\sum_{t=1}^{T} C R\left(S t a r t_{-} I n v_{-} R_{j t}\right)+\sum_{t=1}^{T} \operatorname{Or}\left(A_{j t}\right)+\sum_{t=1}^{T} B C r\left(B L_{-} R_{j t}\right)
$$

The cost Function (2) refers to the various cost incurred in retailer site. The first part represents the initial inventory holding cost. The second part represents the inventory holding cost for each time period. The third part represents ordering cost and fourth part denotes the backorder cost at retailer.

Distributor cost:

$$
\begin{aligned}
& I d(C D)+\sum_{t=1}^{T} C D\left(\text { Start_Inv_D } D_{j t}\right)+\sum_{t=1}^{T} \operatorname{Od}\left(B_{j t}\right)+\sum_{t=1}^{T} B C d\left(B L_{-} D_{j t}\right) \\
& +\sum_{t=1}^{T} C s h i p_{-} D R\left(A_{j t}\right)
\end{aligned}
$$

Function (3) linked to the various cost incurred at distributor site. The first part represents the initial inventory holding cost. The second part represents the inventory holding cost for each time period. The third part represents ordering cost and fourth part denotes the backorder cost at distributor. The fifth part represents the shipment cost of products sent to retailer.

\section{Manufacturer cost:}

$$
\begin{aligned}
& \operatorname{Im}(C M P)+\sum_{i=1}^{i}(C M P)\left(S t a r t_{-} I n v_{-} M_{j t}\right)+\sum_{i=1}^{i} C M \operatorname{Pr}\left(I n v_{-} \text {Dis } A_{i t}+I n v_{-} \text {Dis } B_{i t}+I n v_{-} D i s C_{i t}\right) \\
& +\operatorname{Im}(c j)+c j\left(\frac{I n v_{-} M A_{i t}}{a 1}+\frac{I n v_{-} M B_{i t}}{a 2}+\frac{I n v_{-} M C_{i t}}{a 3}\right)+\sum_{t=1}^{T} \operatorname{PurA}\left(\operatorname{ShipSP} P_{i t}\right) \\
& +\sum_{t=1}^{T} \operatorname{PurB}\left(\operatorname{ShipSP}_{i t}\right)+\sum_{t=1}^{T} \operatorname{PurC}\left(\operatorname{ShiSP}_{i t}\right) \\
& +\sum_{t=1}^{T} B C m\left(B L_{-} M_{j t}\right)+\sum_{t=1}^{T} O m\left(C_{j t}\right)+\sum_{t=1}^{T} C \operatorname{ship} \_M D\left(B_{j t}\right)
\end{aligned}
$$


The cost Functions (4) connected to the cost at the manufacturing site. The first part represents the initial inventory holding cost. The second part represents the inventory holding cost for each time period. The third part represents the holding cost for parts at manufacturer. The fourth part denotes the initial manufacturing cost. The fifth part represents the manufacturing cost of products using the parts from part inventories. The $6^{\text {th }}, 7^{\text {th }}, 8^{\text {th }}$ part represents the purchase cost of parts A, B, C from the supplier. The ninth part represents the backorder cost at the manufacturer. The $10^{\text {th }}$ part represents the ordering cost for the manufacturer. The $11^{\text {th }}$ part denotes the shipment cost for products sent to the distributor.

Collecting cost:

$$
\sum_{t=1}^{T} \operatorname{Cs} \operatorname{Coll}\left(Y_{j t}\right)
$$

The cost Function (5) denotes the collecting cost.

Disassembly cost:

$$
\begin{aligned}
& \sum_{t=1}^{T} C D i s P\left(I n v_{-} D i s_{j t}\right)+\sum_{t=1}^{T} C D i s \operatorname{Pr}\left(I n v_{-} D i s_{i t}\right) \\
& +C s D i s\left(\frac{\sum_{t=1}^{T} I n v_{-} D i s A_{i t}}{a 1}+\frac{\sum_{t=1}^{T} I n v_{-} D i s B_{i t}}{a 2}+\frac{\sum_{t=1}^{T} I n v_{-} D i s C_{i t}}{a 3}\right) \\
& +\sum_{t=1}^{T} C s h i p_{-} D i s D P\left(I_{i t}\right)+\sum_{t=1}^{T} C s h i p_{-} \operatorname{DisREC}\left(E_{i t}\right)+\sum_{t=1}^{T} C s h i p_{-} \operatorname{Dis} P I\left(E_{i t}\right)
\end{aligned}
$$

The cost Function (6) gives the disassembly cost. The first part represents the holding cost of products at disassembly site. The second part represents the holding cost of parts at disassembly site. The third part represents the disassembly cost for parts at disassembly site. The $4^{\text {th }}, 5^{\text {th }}, 6^{\text {th }}$ part represents the shipment cost for the parts sent to disposal site, recycling site and to the part inventory.

Repair site:

$$
\sum_{t=1}^{T} \operatorname{Crep}\left(\operatorname{Inv} \operatorname{Re}_{j}\right)+\sum_{t=1}^{T} d_{j}\left(X_{j t}\right)+\sum_{t=1}^{T} \operatorname{Cship} \_\operatorname{REP}\left(D_{j t}\right)
$$

The cost Function (7) denotes the various costs at repair site. The first part represents the holding cost of products at repair site. The second part represents the repair cost for product at repair site. The third part represents the shipment cost of products sent to manufacturer. 
Disposal cost:

$$
\sum_{i=1}^{T} \operatorname{Cs} D S P\left(\operatorname{ShipDSDP} P_{i t}\right)
$$

The cost Function (8) denotes the disposal cost of parts.

Recycling cost:

$$
\begin{aligned}
& \sum_{t=1}^{T} \operatorname{Crec}\left(I n v_{-} \operatorname{Re} c_{i t}\right)+\sum_{t=1}^{T} \operatorname{CsRcl}\left(\operatorname{ShipDSRCA} A_{i t}+\operatorname{ShipDSRCB} B_{i t}+\operatorname{ShipDSRCC} C_{i t}\right) \\
& +\sum_{t=1}^{T} \operatorname{Cship} \_\operatorname{Re} c P I\left(G_{i t}\right)
\end{aligned}
$$

The cost Function (9) denotes the various costs at recycling site. The first part represents the holding cost of parts at recycling site. The second part represents the recycling cost for parts at recycling site. The third part represents the shipment costs of parts A, B, C sent to part inventory at manufacturer.

Subject to the following constraints:

Initial constraints:

$$
\begin{aligned}
& \text { Start_Inv_R } R_{j t}=I_{r} \quad \forall \quad t=0 \\
& \text { End_Inv_R } R_{j t}=I_{r}-D_{-} R_{j t} \quad \forall \quad t=0 \\
& \text { Start_Inv_D } D_{j t}=I_{d} \quad \forall \quad t=0 \\
& \text { End_Inv_D } D_{j t}=I_{d}-\operatorname{ShipDR} R_{j t} \quad \forall \quad t=0 \\
& \text { Start_Inv_ } M_{j t}=I_{m} \quad \forall t=0 \\
& \text { End_Inv_M } M_{j t}=I_{m}-S_{\text {ShipMD }} \quad \forall \quad t=0
\end{aligned}
$$

The following constraints are set for the time period greater than one:

Retailer constraints:

$$
\text { Start_Inv_ } R_{j t} \leq \text { End_Inv_ } R_{j t-1}+\text { ShipDR } R_{j t-1}
$$

The Constraint (11) shows the starting inventory is always less than equal to the summation of end inventory at retailer and shipment of products from distributor to retailer.

$$
\text { End_Inv_ } R_{j t} \leq \max \left(\text { Start_Inv_ } R_{j t}-D_{-} R_{j t}, 0\right)
$$

Constraint (12) ensures the end inventory should always less than equals to the difference in the starting inventory to the demand at retailer. 


$$
B L_{-} R_{j t} \leq\left|\max \left(D_{-} R_{j t}-S_{t a r t} I n v_{-} R_{j t}, \quad 0\right)\right|
$$

Constraint (13) represents the backorder at retailer.

$$
A_{j t} \leq \max \left(F O Q R-E n d_{-} I n v_{-} R_{j t} \quad, 0\right)
$$

The Constraint (14) denotes the binary decision variable for reorder point at retailer.

$$
\operatorname{ShipDR}_{j t}=F O Q R \quad \forall A_{j t}=1
$$

Constraint (15) represents shipment quantity from distributor to retailer.

\section{Distributor constraints:}

$$
\text { Start_Inv_D } D_{j t} \leq \text { End_Inv_D } D_{j t-1}+\text { ShipMD } D_{j t-1}
$$

The Constraint (16) shows the starting inventory is always less than equal to the summation of end inventory at distributor and shipment of products from manufacturer.

$$
\text { End_Inv_D } D_{j t} \leq \max \left(\operatorname{Start}{ }_{-} I n v_{-} D_{j t}-\operatorname{ShipDR} R_{j t}, 0\right)
$$

Constraint (17) ensures the end inventory less than and equals to the difference in the starting inventory to the products shipped to retailer.

$$
B L_{-} D_{j t} \leq \mid \max \left(\operatorname{ShipDR} R_{j t}-\text { Start_Inv_D }_{j t}, 0\right) \mid
$$

Constraint (18) represents the backorder at distributor.

$$
B_{j t} \leq \max \left(F O Q D-E n d_{-} I n v_{-} D_{j t} \quad, \quad 0\right)
$$

The Constraint (19) denotes the binary decision variable for reorder point at distributor.

$$
\operatorname{ShipMD}_{j t}=F O Q D \quad \forall \quad B_{j t}=1
$$

Constraint (20) represents shipment quantity from manufacturer to distributor.

\section{Manufacturer constraints:}

$$
S t a r t_{-} I n v_{-} M_{j t} \leq E n d_{-} I n v_{-} M_{j t-1}+\frac{I n v_{-} M A_{i t-1}}{a 1}+\frac{I n v_{-} M B_{i t-1}}{a 2}+\frac{I n v_{-} M C_{i t-1}}{a 3}+\text { Ship } \operatorname{Re} p M_{j t-1}
$$


The Constraint (21) shows the starting inventory is always equal to the summation of end inventory at manufacturer, shipment of products from repair site and products made from available parts in part inventory.

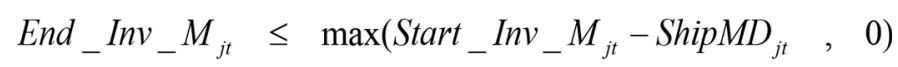

Constraint (22) ensures the end inventory equals to the difference in the starting inventory to the products shipped to distributor.

$$
B L_{-} M_{j t} \leq \mid \max \left(\text { ShipMD }_{j t}-\text { Start_Inv_M }_{j t}, \quad 0\right) \mid
$$

Constraint (23) represents the backorder at manufacturer.

$$
C_{j t} \leq \max \left(F O Q M-S_{\text {Start }} I n v_{-} M_{j t} \quad, \quad 0\right)
$$

The Constraint (24) denotes the binary decision variable for reorder point at manufacturer to the supplier.

$$
M F_{j t}=F O Q M \quad \forall C_{j t}=1
$$

Constraint (25) reflects the need of parts to manufacturer the product.

$$
\begin{array}{ll}
M F A_{i t}=\max \left(M F_{j t-1}(a 1) \quad,\right. & 0) \quad \forall C_{j t}=1 \\
M F B_{i t}=\max \left(M F_{j t-1}(a 2) \quad,\right. & 0) \quad \forall C_{j t}=1 \\
M F C_{i t}=\max \left(M F_{j t-1}(a 3) \quad,\right. & 0) \quad \forall C_{j t}=1
\end{array}
$$

Constraint (26), (27) and (28) denotes the order quantity of parts A, B and C to supplier apart from the part received from recycling site and end of use returns.

$$
\begin{aligned}
& S h i p S P A_{i t}=M F A_{i t-1} \\
& \text { ShipSPB } i t=M F B_{i t-1} \\
& S h i p S P C_{i t}=M F C_{i t-1}
\end{aligned}
$$

Furthermore the Constraint (29), (30), (31) denotes the shipments of parts A, B, C from the supplier.

Collection, Repair and Disassembly site constraints:

$$
Y_{j t}=m 4\left(D_{-} R_{j t-1}\right)
$$




$$
\begin{aligned}
& Z_{j t}=m 6\left(Y_{j t}\right) \\
& X_{j t}=m 5\left(Y_{j t}\right)
\end{aligned}
$$

Constraint (32), (33), (34) states the number of products collected at collection site, number of parts which are disassembled at disassembly site and the number of products at repair site respectively.

$$
I n v_{-} \operatorname{Re} p_{j t}=\left(X_{j t}+I n v_{-} \operatorname{Re} p_{j t-1}\right)-\operatorname{Ship} \operatorname{Re} p M_{j t-1}
$$

Constraint (35) denotes the inventory at repair site which is the difference to the summation of the products repaired at each period and inventory at previous period at repair site to the shipment of products from the repair site to the product inventory at manufacturer.

$$
D_{j t} \leq \max \left(I n v_{-} \operatorname{Re} p j t-S, 0\right)
$$

Constraint (36) is defined to binary decision variable for shipment of products from repair site to the inventory at manufacturer.

$$
\text { Ship } \operatorname{Re} p M_{j t}=S \quad \forall \quad D_{j t}=1
$$

Constraint (37) regulates the shipment of products from repair site to the manufacturer product inventory.

$$
K_{i t} \leq \max \left(Z_{j t}-D I S, 0\right)
$$

Constraint (38) denotes binary decision variable if the parts sent to disassembly is higher than the disassembly capacity.

$$
I n v_{-} D i s_{j t}=\max \left(\left|D I S-Z_{j t}\right| \quad, \quad 0\right) \quad \forall \quad K_{i t}=1
$$

Constraint (39) refers to the products kept in the disassembly site as product.

$$
I n v_{-} D i s_{i t}=\max (D I S * 4 \quad, \quad 0) \quad \forall \quad K_{i t}=1
$$

Constraint (40) refers to the parts kept in the disassembly site after disassembly of products.

$$
I n v_{-} D i s D S_{i t}=I n v_{-} D i s_{i t} * m 1+I n v_{-} D i s D S_{i t-1}-S h i p D S D P_{i t-1}
$$

Constraint (41) ensures the inventory of parts to be sent to disposal site.

$$
I_{i t} \leq \max \left(I n v_{-} \text {DisDS } S_{i t}-\operatorname{MaxDIS} \quad, \quad 0\right)
$$


Constraint (42) denotes binary decision variable if inventory of parts at disassembly site that to be disposed reaches the maximum capacity of disposal site.

$$
\text { ShipDSP } P_{i t}=\text { MaxDis } \quad \forall \quad I_{i t}=1
$$

Constraint (43) refers to the shipment of parts to disposal site.

Recycling site constraints:

$$
\begin{aligned}
& I n v_{-} D i s A_{i t}=\frac{\left(\left(I n v_{-} D i s_{i t} *(1-m 1)\right)\right.}{2} \\
& I n v_{-} \text {DisB } B_{i t}=\frac{I n v_{-} D i s A_{i t}}{2} \\
& I n v_{-} D i s C_{i t}=\frac{I n v_{-} D i s A_{i t}}{2}
\end{aligned}
$$

Furthermore the Constraint (44), (45), (46) reflects the maximum percentage of parts A, B, C kept at disassembly part inventories after the disposal.

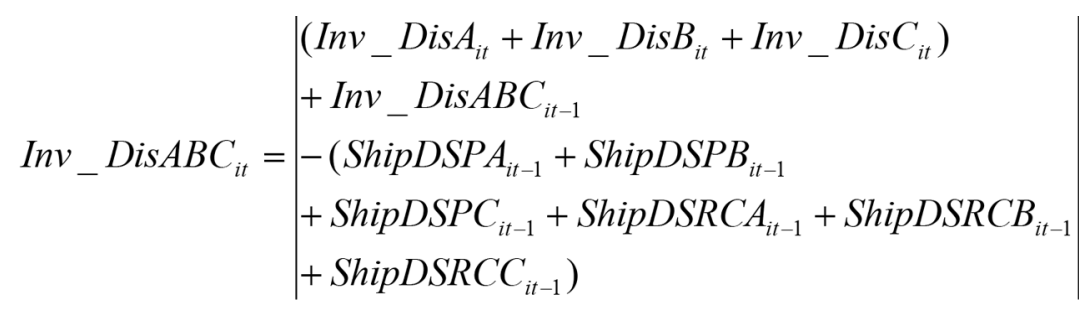

Constraint (47) shows the summation of inventory of parts A, B, C after deducting the parts sent to recycling site and parts sent as end of use returns.

$$
E_{i t} \leq \max \left(I n v_{-} \text {Dis } A B C_{i t}-(\text { ShipDIS_RC_PI }) \quad, \quad 0\right)
$$

Constraint (48) is defined to binary decision variable for summation of inventory of parts exceeds trigger point at disassembly site.

$$
\begin{aligned}
& \operatorname{ShipDSPA} A_{i t}=D S P A^{*} m 2 \quad \forall \quad E_{i t}=1 \\
& \operatorname{ShipDSPB}_{i t}=D S P B^{*} m 2 \quad \forall \quad E_{i t}=1 \\
& \operatorname{ShipDSPC}_{i t}=D S P C^{*} m 2 \quad \forall E_{i t}=1
\end{aligned}
$$

Furthermore the Constraint (49), (50), (51) denotes the parts A, B, C sent to part inventory at manufacturer from disassembly site. 


$$
\begin{array}{lll}
\operatorname{ShipDSRCA}_{i t}=\operatorname{DSRCA}(1-m 2) & \forall & E_{i t}=1 \\
\operatorname{ShipDSRCB}_{i t}=\operatorname{DSRCB}(1-m 2) & \forall & E_{i t}=1 \\
\operatorname{ShipDSRCC}_{i t}=\operatorname{DSRCC} *(1-m 2) & \forall & E_{i t}=1
\end{array}
$$

The Constraint (52), (53), (54) denotes the parts A, B, C sent to recycling site from disassembly site.

$$
\begin{aligned}
& \text { Inv_Re } c_{i t}=\left(\operatorname{ShipDSRCA}_{i t-1}+\operatorname{ShipDSRCB}_{i t-1}+\operatorname{ShipDSRCC}_{i t-1}\right) \\
& +I n v_{-} \operatorname{Re} c_{i t-1}-\left(\operatorname{ShipRCPA}_{i t}+\operatorname{ShipRCPB}_{i t}+\operatorname{ShipRCPC}_{i t}\right)
\end{aligned}
$$

The Constraint (55) governs the total inventory at recycling site that is summation of the shipment of parts from disassembly site and deducting the parts sent to part inventory at manufacturer.

$$
G_{i t} \leq \max \left(I n v_{-} \operatorname{Re} c_{i t}-R, 0\right)
$$

The Constraint (56) is defined to binary decision variable for inventory of parts at recycle site reaches the shipment trigger point.

$$
\begin{aligned}
& S h i p R C P A_{i t}=R C P A \quad \forall \quad G_{i t-1}=1 \\
& S h i p R C P B_{i t}=R C P B \quad \forall \quad G_{i t-1}=1 \\
& S h i p R C P C_{i t}=R C P C \quad \forall \quad G_{i t-1}=1
\end{aligned}
$$

The Constraints (57), (58), (59) denotes the parts A, B, C shipped from recycle site to part inventories A, $\mathrm{B}, \mathrm{C}$ at manufacturing site.

$$
\begin{aligned}
& I n v_{-} M A_{i t}=\operatorname{ShipRCPA} A_{i t-1}+\operatorname{ShipDSPA} A_{i t-1}+\operatorname{ShipSPA} A_{i t-1} \\
& I n v_{-} M B_{i t}=\operatorname{ShipRCPB} B_{i t-1}+\operatorname{ShipDSPB} B_{i t-1}+\operatorname{ShipSPB}_{i t-1} \\
& I n v_{-} M C_{i t}=S h i p R C P C_{i t-1}+\operatorname{ShipDSPC} C_{i t-1}+\operatorname{ShipSPC}_{i t-1}
\end{aligned}
$$

In addition the Constraints (60), (61), (62) defines the part inventory A, B, C at the manufacturer it is the sum of parts received as end of use returns, parts from recycling site, and parts shipped from the supplier. 


\section{Computational Results}

The numerical examples are presented in this section. Here a product consists of three Parts A (which of 2nos.); B and C were selected for 12 multiple periods. The demand of the product follows a normal with a mean of 2500 and deviation of 500 for 12 periods. The manufacturer has to know how much should to be manufacture in multiple periods based on the demand by adopting the FOQ inventory policy at different sites with their capacity constraints. In addition, it is important how much of parts should be purchased from the supplier at the given 12 periods. The required parameters are given in the Appendix. The proposed model is solved by IBM ILOG CPLEX OPL studio (version 12). The results obtained for various decision variables are written in the Table 2.

\begin{tabular}{|c|c|c|c|c|c|c|c|c|c|c|c|c|}
\hline \multirow[t]{2}{*}{$\begin{array}{l}\text { Decision } \\
\text { variable }\end{array}$} & \multicolumn{12}{|c|}{ Period } \\
\hline & 1 & 2 & 3 & 4 & 5 & 6 & 7 & 8 & 9 & 10 & 11 & 12 \\
\hline Demand & 2043 & 2347 & 2540 & 2499 & 2862 & 2967 & 2743 & 2521 & 2506 & 3558 & 2135 & 2844 \\
\hline \multicolumn{13}{|c|}{ Retailer } \\
\hline Start_Inv_R $\mathrm{R}_{i t}$ & 7000 & 4957 & 6610 & 4070 & 5571 & 6709 & 7742 & 4999 & 6478 & 7972 & 4414 & 6279 \\
\hline$A_{j t}$ & 0 & 1 & 0 & 1 & 1 & 1 & 0 & 1 & 1 & 0 & 1 & 1 \\
\hline End_Inv_R $\mathrm{R}_{i t}$ & 4957 & 2610 & 4070 & 1571 & 2709 & 3742 & 4999 & 2478 & 3972 & 4414 & 2279 & 3435 \\
\hline$B L \_R_{j t}$ & 0 & 0 & 0 & 0 & 0 & 0 & 0 & 0 & 0 & 0 & 0 & 0 \\
\hline$S_{h i p D R_{j t}}$ & 0 & 4000 & 0 & 4000 & 4000 & 4000 & 0 & 4000 & 4000 & 0 & 4000 & 4000 \\
\hline \multicolumn{13}{|c|}{ Distributor } \\
\hline Start_Inv_D $D_{i t}$ & 8000 & 8000 & 9000 & 9000 & 5000 & 6000 & 7000 & 7000 & 8000 & 9000 & 9000 & 5000 \\
\hline$B_{j t}$ & 0 & 1 & 0 & 0 & 1 & 1 & 0 & 1 & 1 & 0 & 0 & 1 \\
\hline End_Inv_D ${ }_{i t}$ & 8000 & 4000 & 9000 & 5000 & 1000 & 2000 & 7000 & 3000 & 4000 & 9000 & 5000 & 1000 \\
\hline$B L \_D_{j t}$ & 0 & 0 & 0 & 0 & 0 & 0 & 0 & 0 & 0 & 0 & 0 & 0 \\
\hline $\operatorname{Ship} M D_{j t}$ & 0 & 5000 & 0 & 0 & 5000 & 5000 & 0 & 5000 & 5000 & 0 & 0 & 5000 \\
\hline \multicolumn{13}{|c|}{ Manufacturer } \\
\hline Start_Inv_M $M_{j t}$ & 9000 & 9000 & 4000 & 4000 & 4000 & 1450 & 18450 & 36900 & 52850 & 49800 & 49800 & 52750 \\
\hline$C_{j t}$ & 0 & 0 & 1 & 1 & 1 & 1 & 0 & 0 & 0 & 0 & 0 & 0 \\
\hline$E n d \_I n v \_M_{j t}$ & 9000 & 4000 & 4000 & 4000 & 0 & 0 & 18450 & 31900 & 47850 & 49800 & 49800 & 47750 \\
\hline$B L \_M_{i t}$ & 0 & 0 & 0 & 0 & 1000 & 3550 & 0 & 0 & 0 & 0 & 0 & 0 \\
\hline \multicolumn{13}{|c|}{ Collection site } \\
\hline$Y_{j t}$ & 0 & 817.2 & 938.8 & 1016 & 999.6 & 1144.8 & 1186.8 & 1097.2 & 1008.4 & 1002.4 & 1423.2 & 854 \\
\hline$X_{j t}$ & 0 & 245.16 & 281.64 & 304.8 & 299.88 & 343.44 & 356.04 & 329.16 & 302.52 & 300.72 & 426.96 & 256.22 \\
\hline$Z_{j t}$ & 0 & 572.04 & 657.16 & 711.2 & 699.72 & 801.36 & 830.76 & 768.04 & 705.88 & 701.68 & 996.24 & 597.80 \\
\hline
\end{tabular}




\begin{tabular}{|c|c|c|c|c|c|c|c|c|c|c|c|c|}
\hline \multicolumn{13}{|c|}{ Repair site } \\
\hline$I n v_{-} R e p_{j t}$ & 0 & 245.16 & 526.8 & 831.6 & 1131.4 & 474.92 & 830.96 & 1160.1 & 462.64 & 763.36 & 1190.3 & 446.54 \\
\hline$D_{j t}$ & 0 & 0 & 0 & 0 & 1 & 0 & 0 & 1 & 0 & 0 & 1 & 0 \\
\hline ShipRepM $M_{j t}$ & 0 & 0 & 0 & 0 & 1000 & 0 & 0 & 1000 & 0 & 0 & 1000 & 0 \\
\hline \multicolumn{13}{|c|}{ Disassembly sites } \\
\hline$I n v_{-} D i s_{i t}$ & 0 & 2288.16 & 2628.6 & 2844.8 & 2798.8 & 3200 & 3200 & 3195.2 & 2823.5 & 2806.7 & 3200 & 3176.16 \\
\hline$K_{i t}$ & 0 & 0 & 0 & 0 & 0 & 1 & 1 & 0 & 0 & 0 & 1 & 0 \\
\hline$I n v_{-} D i s_{j t}$ & 0 & 0 & 0 & 0 & 0 & 1.36 & 30.76 & 0 & 0 & 0 & 196.24 & 0 \\
\hline$I n v_{-} D i s A_{i t}$ & 0 & 686.45 & 788.59 & 853.4 & 839.66 & 960 & 960 & 958.56 & 847.06 & 842.02 & 960 & 952.85 \\
\hline Inv_DisB ${ }_{i t}$ & 0 & 343.22 & 394.3 & 426.72 & 419.83 & 480 & 480 & 479.28 & 423.53 & 421.01 & 480 & 476.42 \\
\hline$I n v \_D i s C_{i t}$ & 0 & 343.22 & 394.3 & 426.72 & 419.83 & 480 & 480 & 479.28 & 423.53 & 421.01 & 480 & 476.42 \\
\hline$I n v \_D i s A B C_{i t}$ & 0 & 1372.9 & 2950.1 & 4657 & 4336.3 & 4256.3 & 4176.3 & 4093.4 & 3787.6 & 5471.6 & 5391.6 & 5297.2 \\
\hline \multicolumn{13}{|c|}{ Disassembly to part inventory } \\
\hline$E_{i t}$ & 0 & 0 & 0 & 1 & 1 & 1 & 1 & 1 & 0 & 1 & 1 & 1 \\
\hline $\operatorname{ShipDSP}_{i t}$ & 0 & 0 & 0 & 300 & 300 & 300 & 300 & 300 & 0 & 300 & 300 & 300 \\
\hline $\operatorname{ShipDSPB}_{i t}$ & 0 & 0 & 0 & 150 & 150 & 150 & 150 & 150 & 0 & 150 & 150 & 150 \\
\hline ShipDSPC ${ }_{i t}$ & 0 & 0 & 0 & 150 & 150 & 150 & 150 & 150 & 0 & 150 & 150 & 150 \\
\hline$R 1_{\text {it }}$ & 0 & 0 & 0 & 300 & 300 & 300 & 300 & 300 & 0 & 300 & 300 & 300 \\
\hline $\mathrm{R} 2_{i t}$ & 0 & 0 & 0 & 150 & 150 & 150 & 150 & 150 & 0 & 150 & 150 & 150 \\
\hline$R 3_{i t}$ & 0 & 0 & 0 & 150 & 150 & 150 & 150 & 150 & 0 & 150 & 150 & 150 \\
\hline \multicolumn{13}{|c|}{ Disassembly to recycling site } \\
\hline ShipDSRCA $A_{i t}$ & 0 & 0 & 0 & 700 & 700 & 700 & 700 & 700 & 0 & 700 & 700 & 700 \\
\hline ShipDSRCB $_{i t}$ & 0 & 0 & 0 & 350 & 350 & 350 & 350 & 350 & 0 & 350 & 350 & 350 \\
\hline ShipDSRCC ${ }_{i t}$ & 0 & 0 & 0 & 350 & 350 & 350 & 350 & 350 & 0 & 350 & 350 & 350 \\
\hline \multicolumn{13}{|c|}{ Recycling site to part inventory } \\
\hline$I n v_{-} R e c_{i t}$ & 0 & 0 & 0 & 0 & 1400 & 2800 & 2200 & 1600 & 3000 & 1000 & 2400 & 1800 \\
\hline$G_{i t}$ & 0 & 0 & 0 & 0 & 0 & 1 & 1 & 0 & 1 & 0 & 1 & 0 \\
\hline ShipRCPA $A_{i t}$ & 0 & 0 & 0 & 0 & 0 & 0 & 1000 & 1000 & 0 & 1000 & 0 & 1000 \\
\hline ShipRCPB $B_{i t}$ & 0 & 0 & 0 & 0 & 0 & 0 & 500 & 500 & 0 & 500 & 0 & 500 \\
\hline ShipRCPC $C_{i t}$ & 0 & 0 & 0 & 0 & 0 & 0 & 500 & 500 & 0 & 500 & 0 & 500 \\
\hline$E 1_{i t}$ & 0 & 0 & 0 & 0 & 0 & 0 & 1000 & 1000 & 0 & 1000 & 0 & 1000 \\
\hline$E 2_{i t}$ & 0 & 0 & 0 & 0 & 0 & 0 & 500 & 500 & 0 & 500 & 0 & 500 \\
\hline$E 3_{i t}$ & 0 & 0 & 0 & 0 & 0 & 0 & 500 & 500 & 0 & 500 & 0 & 500 \\
\hline \multicolumn{13}{|c|}{ Disposal site } \\
\hline$I n v_{-} D i s D S_{i t}$ & 0 & 915.26 & 1966.7 & 3104.6 & 4224.1 & 5504.1 & 1784.1 & 3062.2 & 4191.6 & 5314.3 & 1594.3 & 2864.83 \\
\hline$I_{i t}$ & 0 & 0 & 0 & 0 & 0 & 1 & 0 & 0 & 0 & 1 & 0 & 0 \\
\hline ShipDSDP $_{i t}$ & 0 & 0 & 0 & 0 & 0 & 5000 & 0 & 0 & 0 & 5000 & 0 & 0 \\
\hline
\end{tabular}




\begin{tabular}{|c|c|c|c|c|c|c|c|c|c|c|c|c|}
\hline \multicolumn{13}{|c|}{ Manufacturer inventory } \\
\hline$I n v_{-} M A_{i t}$ & 0 & 0 & 0 & 0 & 300 & 12300 & 12300 & 13300 & 1300 & 0 & 1300 & 300 \\
\hline$I n v_{-} M B_{i t}$ & 0 & 0 & 0 & 0 & 150 & 6150 & 6150 & 6650 & 650 & 0 & 650 & 150 \\
\hline$I n v_{-} M C_{i t}$ & 0 & 0 & 0 & 0 & 150 & 6150 & 6150 & 6650 & 650 & 0 & 650 & 150 \\
\hline$M F_{j t}$ & 0 & 0 & 6000 & 6000 & 6000 & 6000 & 0 & 0 & 0 & 0 & 0 & 0 \\
\hline$M F A_{i t}$ & 0 & 0 & 0 & 12000 & 12000 & 12000 & 0 & 0 & 0 & 0 & 0 & 0 \\
\hline$M F B_{i t}$ & 0 & 0 & 0 & 6000 & 6000 & 6000 & 0 & 0 & 0 & 0 & 0 & 0 \\
\hline$M F C_{i t}$ & 0 & 0 & 0 & 6000 & 6000 & 6000 & 0 & 0 & 0 & 0 & 0 & 0 \\
\hline$S 1_{\text {it }}$ & 0 & 0 & 0 & 12000 & 12000 & 12000 & 0 & 0 & 0 & 0 & 0 & 0 \\
\hline$S 2_{i t}$ & 0 & 0 & 0 & 6000 & 6000 & 6000 & 0 & 0 & 0 & 0 & 0 & 0 \\
\hline$S 3_{i t}$ & 0 & 0 & 0 & 6000 & 6000 & 6000 & 0 & 0 & 0 & 0 & 0 & 0 \\
\hline ShipSPA $A_{i t}$ & 0 & 0 & 0 & 0 & 12000 & 12000 & 12000 & 0 & 0 & 0 & 0 & 0 \\
\hline ShipSPB ${ }_{i t}$ & 0 & 0 & 0 & 0 & 6000 & 6000 & 6000 & 0 & 0 & 0 & 0 & 0 \\
\hline ShipSPC $C_{i t}$ & 0 & 0 & 0 & 0 & 6000 & 6000 & 6000 & 0 & 0 & 0 & 0 & 0 \\
\hline
\end{tabular}

Table 2. Computational Result

\section{Sensitivity Analysis}

In order to validate the proposed model, sensitivity analysis is performed. First part of the analysis will focus on the inventory of product and parts and second part of analysis on profit of the company. The analysis is done for various percent of total returns of the product. It is seen that the end period inventory at retailer and distributor are not having much effect at multiple periods because the returns from the retailer to distributor and distributor to manufactures are not taken in to account. But the end period at manufacturer is important as the inventory becomes high after certain period as shown in the Figure 2. This illustrates that manufacturer has to control their inventory cost beyond the half of their period chosen. (In this case for 12 periods, half of the above six periods the inventories are having higher values). When the analysis is taken for parts of the product obtained at the disassembly site at multiple periods, the inventory of part is increasing at disassembly site for smaller percent of total returns as shown in the Figure 3. For higher percentage of total returns, the inventory of parts become constant irrespective of the number of periods. It is expected that by increasing the amount of returns at multiple periods, the inventory of parts will also increase. However it is noticed that after certain percent of total returns of the product, the inventory of parts at disassembly site remain constant. Hence the inventory cost of parts at disassembly site will not have any impact on the profit, beyond certain percent of total returns. 


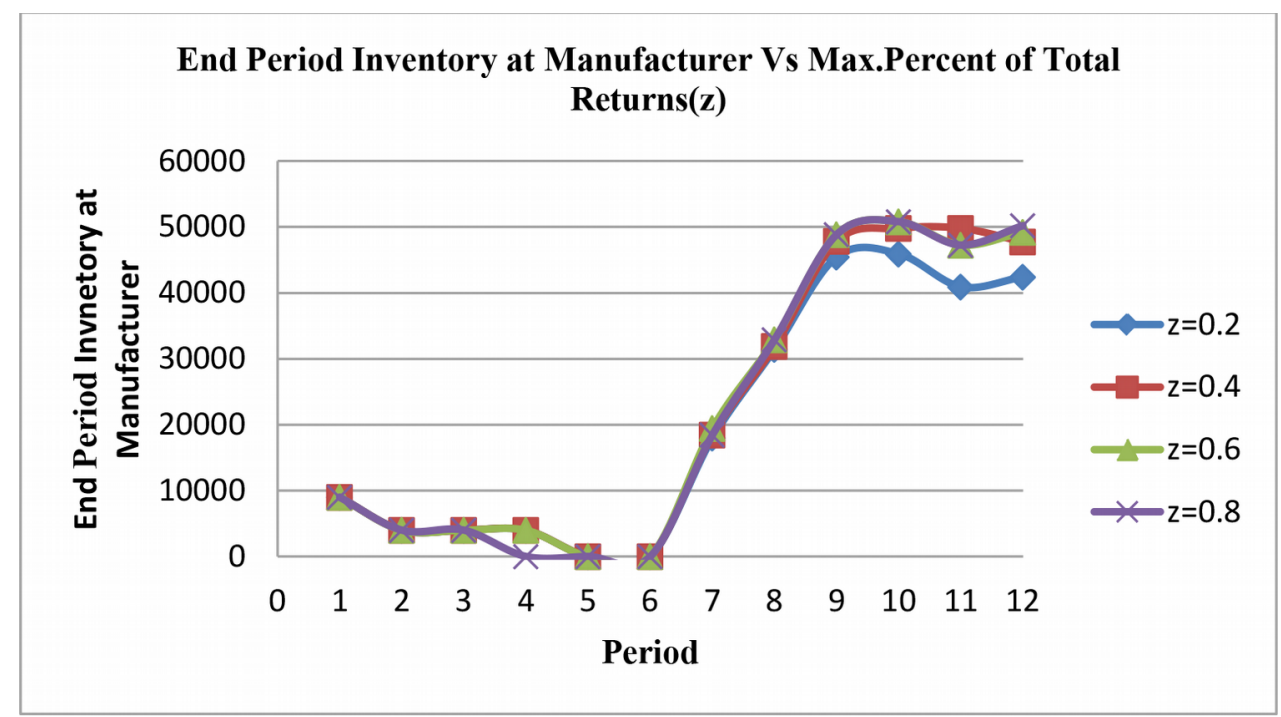

Figure 2. End Period Inventory at Manufacturer at multiple period

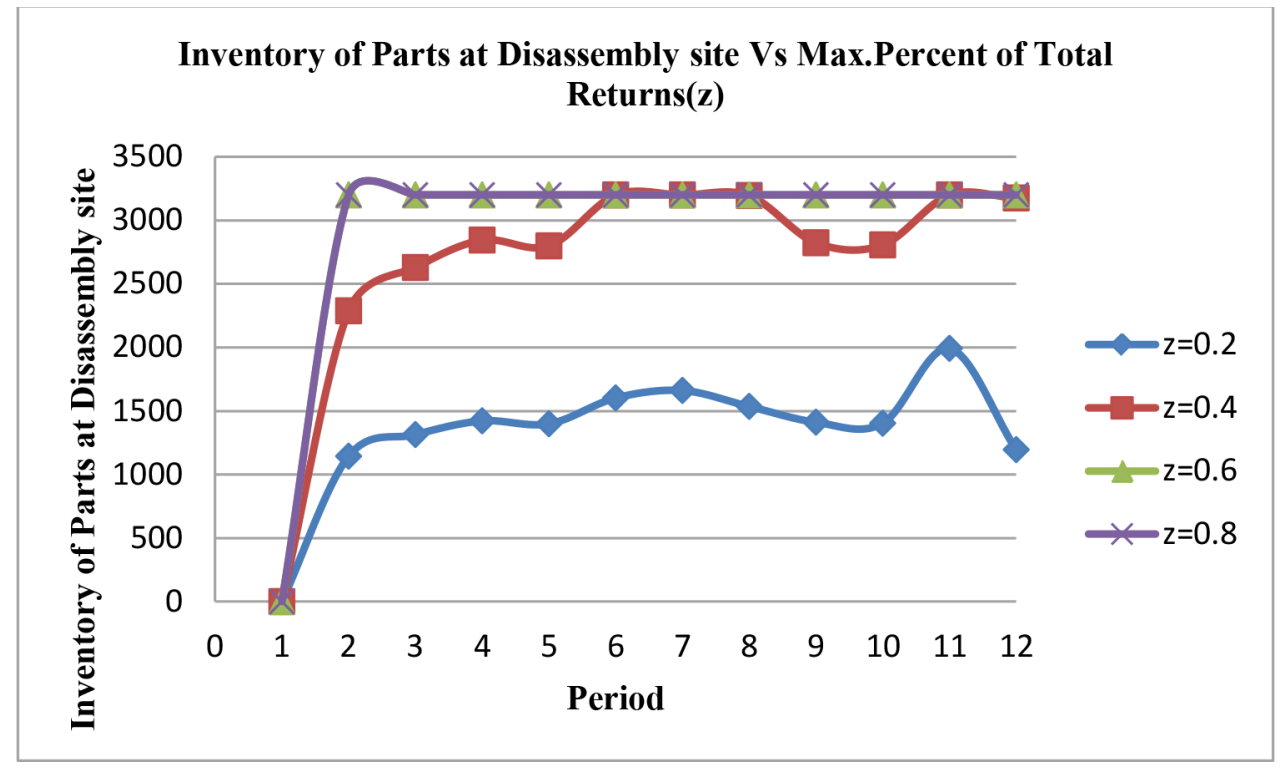

Figure 3. Inventory of parts at Disassembly site at multiple period

To better understand the influencing characteristics of parameters on profit at multiple periods, among all the parameter in the model, Percentage of Total returns of Product, Disposal of parts and product obtained disassembly site are critical ones. One could obtain an important observation from Figure 4 that profit will have minimum value if the percentage of Total returns $(z)$ and percentage of product obtained at disassembly site are same. Since the cost of disassembling the product at disassembly site is greater than the cost of repairing the product in the repair site, it is expected that the profit will decrease when more products are sent to disassembly site. 


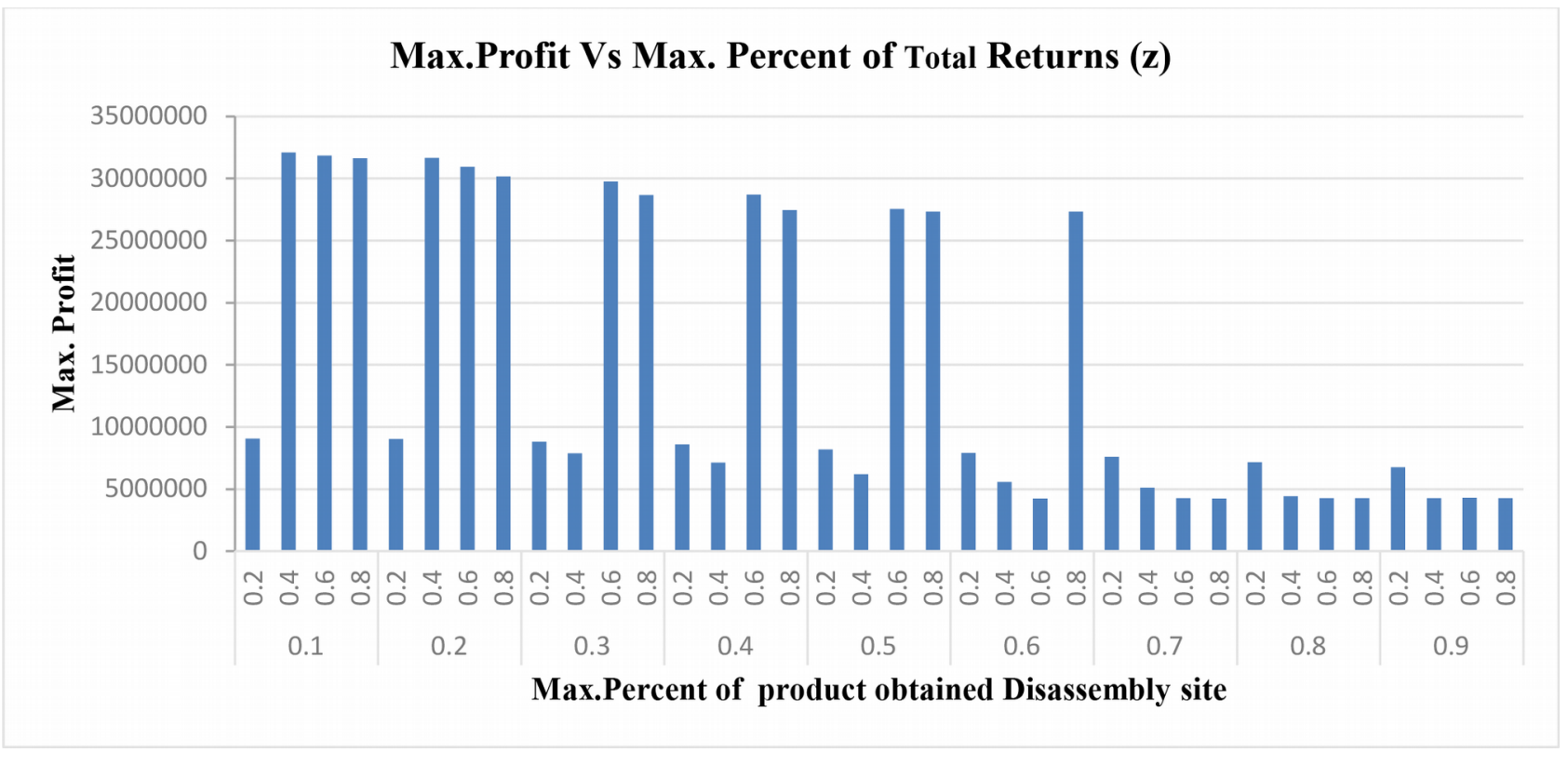

Figure 4. Profit Vs Percent of Total Returns of the product

From Figure 5, it is noticed that for higher percentage values of product obtained in disassembly site a minimum profit occurred when less percentage of parts are sent to disposal site. In other words, the manufacture will have a maximum profit at more parts sent to disposal site for less number of products obtained at disassembly site.

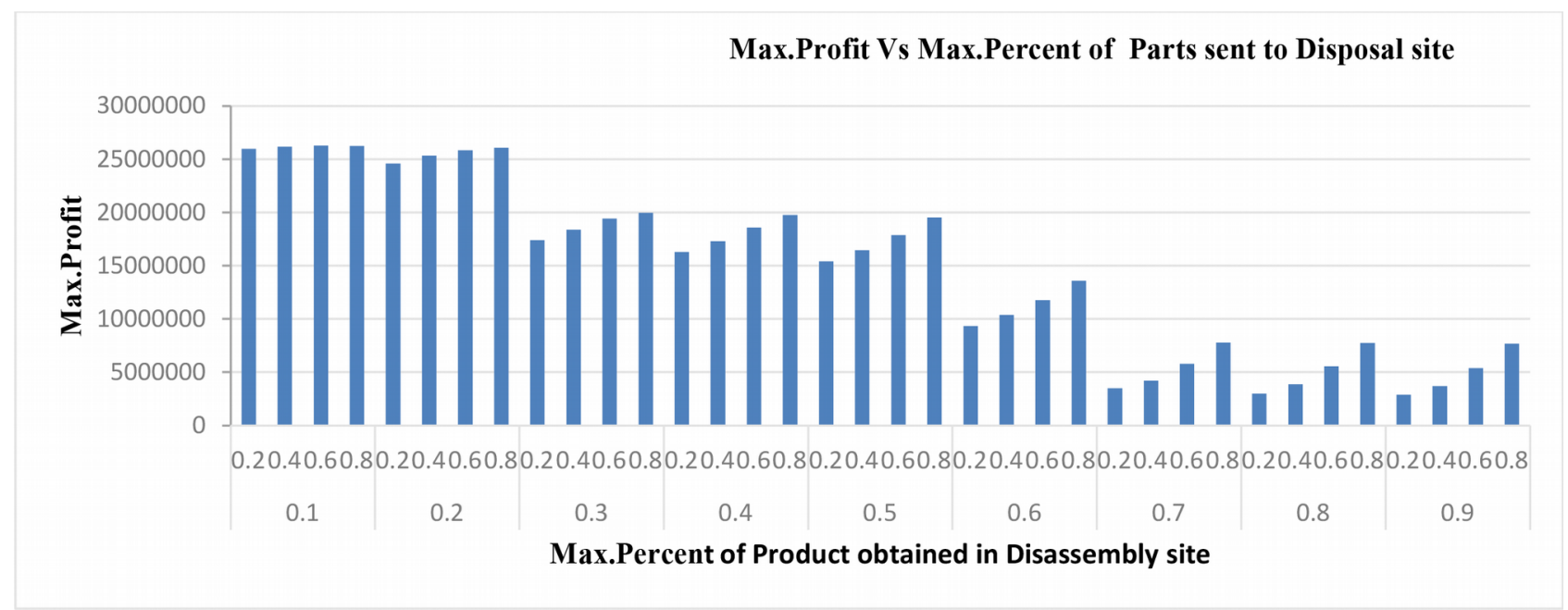

Figure 5. Profit Vs Percent of Parts sent to Disposal site 


\section{Conclusions and Future Research}

The main contribution of the paper lies in designing and solving the problems in recovery of product with standard fixed order inventory policy in multiple periods. The proposed model addresses one product with three major parts. This model was solved using IBM ILOG CPLEX OPL studio (version 2012). The computational result of the decision variables at different sites of the CLSC for the period length of 12 is analysed. To validate the results, a sensitivity analysis was performed by considering the different percent of total returns of the product along with percentage of product obtained at disassembly site and percentage of parts sent to disposal site for multiple periods. The result of the analysis shows that manufacturer inventory stabilizes within one half of the number of periods considered. Also the inventory cost of parts at disassembly site does not have any impact on the profit, beyond certain percent of total returns. We also observed that minimum profit of the supply chain will occur when the percent of total returns and percentage of product obtained at the disassembly site are same.

The present work of the above said model has some limitations in which only one product is considered but this can be relaxed to multi product and parts, multi echelon sites for multiple periods. This paper addresses fixed order inventory policy for positioning of inventory in CLSC. It can be extended to periodic review policy also. Our experience in the current model shows it is computational intensive even for solving small scale problem. Hence meta heuristic approaches like Genetic Algorithms, Ant colony optimizations can be developed to address large scale instances.

\section{References}

Ahiska, S.S., \& King, R.E. (2010). Life cycle inventory policy characterizations for a single-product recoverable system. International Journal of Production Economics, 124(1), 51-61.

https://doi.org/10.1016/j.ijpe.2009.08.033

Amin, S.H., \& Zhang, G. (2012a). An integrated model for closed-loop supply chain configuration and supplier selection: Multi-objective approach. Expert Systems with Applications, 39(8), 6782-6791. https://doi.org/10.1016/j.eswa.2011.12.056

Amin, S.H., \& Zhang, G. (2012b). A proposed mathematical model for closed-loop network configuration based on product life cycle. International Journal of Advanced Manufacturing Technology, 58(5-8), 791-801. https://doi.org/10.1007/s00170-011-3407-2 
Amin, S.H., \& Zhang, G. (2014). Closed-loop supply chain network configuration by a multi-objective mathematical model. International Journal of Business Performance and Supply Chain Modelling, 6(1), 1-15. https://doi.org/10.1504/IJBPSCM.2014.058890

Benedito, E., \& Corominas, A. (2010). Optimal manufacturing and remanufacturing capacities of systems with reverse logistics and deterministic uniform demand. Journal of Industrial Engineering and Management, 3(1), 33-53. https://doi.org/10.3926/jiem.2010.v3n1.p33-53

Cardoso, S.R., Barbosa-Póvoa, A.P.F.D., \& Relvas, S. (2013). Design and planning of supply chains with integration of reverse logistics activities under demand uncertainty. European Journal of Operations Research, 226, 436-451. https://doi.org/10.1016/j.ejor.2012.11.035

El-Sayed, M., Afia, N., \& El-Kharbotly, A. (2010). A stochastic model for forward-reverse logistics network design under risk. Computers \& Industrial Engineering, 58(3), 423-431.

https://doi.org/10.1016/j.cie.2008.09.040

Fleischmann, M., Bloemhof-Ruwaard, J.M., Dekker, R., Van der Laan, E., Van Nunen, J.A., \& Van Wassenhove, L.N. (1997). Quantitative models for reverse logistics: A review. European Journal of Operational Research, 103(1), 1-17. https://doi.org/10.1016/S0377-2217(97)00230-0

Georgiadis, P., Vlachos, D., \& Tagaras, G. (2006). The impact of product lifecycle on capacity planning of closed-loop supply chains with remanufacturing. Production and Operations Management, 15(4), 514-527. https://doi.org/10.1111/j.1937-5956.2006.tb00160.x

Jindal, A., Sangwan, K.S., \& Saxena, S. (2015). Network design and optimization for multi-product, multi-time, multi-echelon closed-loop supply chain under uncertainty. Procedia CIRP, 29, 656-661. https://doi.org/10.1016/j.procir.2015.01.024

Kannan, G., Noorul-Haq, A., \& Devika, M. (2009). Analysis of closed loop supply chain using genetic algorithm and particle swarm optimization. International Journal of Production Research, 47(5), 1175-1200. https://doi.org/10.1080/00207540701543585

Lee, J.E., Gen, M., \& Rhee, K.G. (2008). Reverse logistics network problem using priority-based genetic algorithm. International Journal of Information Systems for Logistics and Management, 4(1), 61-71.

Mishra, V.K. (2013). An inventory model of instantaneous deteriorating items with controllable deterioration rate for time dependent demand and holding cost. Journal of Industrial Engineering and Management, 6(2), 495-506. https://doi.org/10.3926/jiem.530 
Mitra, S. (2012). Inventory management in a two-echelon closed-loop supply chain with correlated demands and returns. Computers \& Industrial Engineering, 62(4), 870-879.

https://doi.org/10.1016/j.cie.2011.12.008

Özceylan, E., \& Paksoy, T. (2013).A mixed integer programming model for a closed-loop supply-chain network. International Journal of Production Research, 51(3), 718-734.

https://doi.org/10.1080/00207543.2012.661090

Rogers, D.S., \& Tibben-Lembke, R. (2001). An examination of reverse logistics Practices. Journal of Business Logistics, 22(2), 129-148. https://doi.org/10.1002/j.2158-1592.2001.tb00007.x

Roghanian, E., \& Pazhoheshfar, P. (2014). An optimization model for reverse logistics network under stochastic environment by using genetic algorithm. Journal of Manufacturing Systems, 33(3), 348-356. https://doi.org/10.1016/j.jmsy.2014.02.007

Saeedi, S., Mohammadi, M., \& Torabi, S. (2015). A De Novo programming approach for a robust closed-loop supply chain network design under uncertainty: An M/M/1 queuing model. International Journal of Industrial Engineering Computations, 6(2), 211-228. https://doi.org/10.5267/j.ijiec.2014.11.002

Sasikumar, A., Natarajan., K., \& Ramasubramaniam, M. (2016). An Inventory Model for a Closed Loop Supply Chain Considering Product Life Cycle in a Discrete Period. International Conference on Systems, Science, Control, Communication, Engineering and Technology. 165-176.

Sasikumar, P., \& Kannan, G. (2008a). Issues in reverse supply chains, part I: end-of-life product recovery and inventory management - an overview. International Journal of Sustainable Engineering, 1(3), 154-172. https://doi.org/10.1080/19397030802433860

Sasikumar, P., \& Kannan, G. (2008b).Issues in reverse supply chains, part II: reverse distribution issues-an overview. International Journal of Sustainable Engineering, 1(4), 234-249.

https://doi.org/10.1080/19397030802509974

Sasikumar, P., \& Kannan, G. (2009).Issues in reverse supply chain, part III: classification and simple analysis. International Journal of Sustainable Engineering, 2(1), 2-27. https://doi.org/10.1080/19397030802673374

Sasikumar, P., Kannan, G., \& Haq, A.N. (2010). A multi-echelon reverse logistics network design for product recovery - a case of truck tire remanufacturing. International Journal of Advanced Manufacturing Technology, 49(9-12), 1223-1234. https://doi.org/10.1007/s00170-009-2470-4 
Shi, J., Zhang, G., \& Sha, J. (2011). Optimal production planning for a multi-product closed loop system with uncertain demand and return. Computers \& Operations Research, 38(3), 641-650. https://doi.org/10.1016/j.cor.2010.08.008

Srivastava, S.K., \& Srivastava, R.K. (2006). Managing product returns for reverse logistics. International Journal of Physical Distribution \& Logistics Management, 36(7), 524-546.

https://doi.org/10.1108/09600030610684962

Subramanian, P., Ramkumar, N., Narendran, T.T., \& Ganesh, K. (2013). PRISM: PRIority based Simulated annealing for a closed loop supply chain network design problem. Applied Soft Computing, 13(2), 1121-1135. https://doi.org/10.1016/j.asoc.2012.10.004

Thierry, M., Salomon, M., Van Nunen, J., \& Van Wassenhove, L. (1995). Strategies issues in product recovery management. California Management Review, 37(2), 114-135. https://doi.org/10.2307/41165792 


\section{Appendix}

\begin{tabular}{|c|c|c|}
\hline \multicolumn{3}{|c|}{ Appendix } \\
\hline$D \_R_{j t}$ & Demand at retailer $[2043,2347,2570,2499,2862,2967,2743,2521,2506,3558,2135,2844]$; & \\
\hline$I_{r}$ & Initial inventory at retailer & 7000 \\
\hline$I_{d}$ & Initial inventory at distributor & 8000 \\
\hline$I_{m}$ & Initial inventory at manufacturer & 9000 \\
\hline sj & Unit selling price of the product & 1500 \\
\hline cj & Unit direct manufacturing cost of a product & 30 \\
\hline$d j$ & Unit repair cost of a product & 1 \\
\hline $\mathrm{Or}$ & Ordering cost for retailer & 4000 \\
\hline Od & Ordering cost for distributor & 4000 \\
\hline$O m$ & Ordering cost for manufacturer & 4000 \\
\hline Cship_DR & Total shipment cost for products from distributor to retailer & 8000 \\
\hline Cship_MD & Total shipment cost for products from manufacturer to distributor & 8000 \\
\hline Cship_DisREC & Total shipment cost for parts from disassembly to recycle site & 5000 \\
\hline Cship_DisPI & Total shipment cost for parts from disassembly to Part inventory & 5000 \\
\hline Cship_RecPI & Total shipment cost for parts from recycle to Part inventory & 5000 \\
\hline Cship_DisDP & Total shipment cost for parts from disassembly to Disposal site & 5000 \\
\hline Cship_REP & Total shipment cost for product from repair site to manufacturer & 5000 \\
\hline DIS & Maximum capacity of the disassembly site & 800 \\
\hline CsColl & Unit collecting cost & 1 \\
\hline CsDis & Unit disassembly cost & 3 \\
\hline CsDSP & Unit disposal cost & 2 \\
\hline CsR $d$ & Unit recycle cost & 2 \\
\hline$a 1$ & Unit requirements of Part A to produce one unit of product $j$ & 2 \\
\hline$a 2$ & Unit requirements of Part B to produce one unit of product $j$ & 1 \\
\hline a3 & Unit requirements of Part $\mathrm{C}$ to produce one unit of product $j$ & 1 \\
\hline $\operatorname{Pur} A$ & Unit purchase cost of part A from supplier & 15 \\
\hline Pur B & Unit purchase cost of part B from supplier & 20 \\
\hline Pur $C$ & Unit purchase cost of part $C$ from supplier & 20 \\
\hline$m 1$ & Maximum percentage of parts sent to disposal site & 0.4 \\
\hline$m 2$ & Maximum percentage of end of use returns & 0.3 \\
\hline$m 3$ & Maximum percentage of end of life returns & 0.3 \\
\hline$m 4$ & Maximum percentage of returns & 0.4 \\
\hline$m 5$ & Maximum percentage of product sent to repair site & 0.3 \\
\hline$m 6$ & Maximum percentage of product sent to disassembly site & 0.7 \\
\hline CR & Unit inventory cost at retailer & 0.3 \\
\hline$C D$ & Unit inventory cost at distributor & 0.3 \\
\hline$C M P$ & Unit inventory cost for product at manufacturer & 0.3 \\
\hline$C M P r$ & Unit inventory cost for part at manufacturer & 0.1 \\
\hline CDisP & Unit inventory cost at disassembly site for product & 0.3 \\
\hline
\end{tabular}




\begin{tabular}{|c|c|c|}
\hline \multicolumn{3}{|c|}{ Appendix } \\
\hline CDisPr & Unit inventory cost at disassembly site for part & 0.1 \\
\hline Crep & Unit inventory cost at repair site & 0.1 \\
\hline Crec & Unit inventory cost at recycling site & 0.1 \\
\hline$B C r$ & Back order cost at retailer & 0.5 \\
\hline$B C d$ & Back order cost at distributor & 0.5 \\
\hline$B C m$ & Back order cost at manufacturer & 0.5 \\
\hline$F O Q R$ & Fixed order quantity for retailer & 4000 \\
\hline FOQD & Fixed order quantity for distributor & 5000 \\
\hline FOQm & Fixed order quantity for manufacturer & 6000 \\
\hline$S$ & Maximum capacity of repair site & 1000 \\
\hline $\mathrm{R}$ & Maximum capacity of recycling site & 2000 \\
\hline MaxDis & Shipment capacity of truck disassembly to disposal site & 5000 \\
\hline$D S P A$ & Truck capacity of part A from disassembly to disposal site & 1000 \\
\hline$D S P B$ & Truck capacity of part B from disassembly to disposal site & 500 \\
\hline$D S P C$ & Truck capacity of part $C$ from disassembly to disposal site & 500 \\
\hline DSRCA & Truck capacity of Part A from disassembly to recycling site & 1000 \\
\hline $\operatorname{DSRCB}$ & Truck capacity of Part B from disassembly to recycling site & 500 \\
\hline DSRCC & Truck capacity of Part C from disassembly to recycling site & 500 \\
\hline $\mathrm{RCPA}$ & Truck capacity of Part A from recycling to part inventory & 1000 \\
\hline $\mathrm{RCPB}$ & Truck capacity of Part B from recycling to part inventory & 500 \\
\hline $\mathrm{RCPC}$ & Truck capacity of Part C from recycling to part inventory & 500 \\
\hline ShipDIS_RC_PI & Shipment trigger point for parts from disassembly site to recycle and part inventory & 4000 \\
\hline
\end{tabular}

\section{Journal of Industrial Engineering and Management, 2017 (www.jiem.org)}

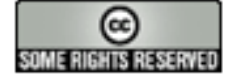

Article's contents are provided on an Attribution-Non Commercial 3.0 Creative commons license. Readers are allowed to copy, distribute and communicate article's contents, provided the author's and Journal of Industrial Engineering and Management's names are included. It must not be used for commercial purposes. To see the complete license contents, please visit http://creativecommons.org/licenses/by-nc/3.0/. 